\title{
Comparative analysis of observer-based LQR and LMI controllers of an inverted pendulum
}

\author{
Nura Musa Tahir ${ }^{1}$, Mustapha Muhammad ${ }^{2}$, Musa Idi ${ }^{3}$, Salinda Buyamin ${ }^{4}$, \\ Ladan Maijama'a ${ }^{5}$, Sa'id Musa Yarima $^{6}$ \\ ${ }^{1,3}$ Department of Mechatronics and System Engineering, Abubakar Tafawa Balewa University, Bauchi, Nigeria \\ ${ }^{2}$ Department of Mechatronics, Bayero University Kano, Nigeria \\ ${ }^{4}$ Division of Control and Mechatronics Engineering, School of Electrical Engineering, Faculty of Engineering, \\ Universiti Teknologi Malaysia, Johor, Malaysia \\ ${ }^{5}$ Department of Electrical and Electronics Engineering, Federal Polytechnic, Bauchi, Nigeria \\ ${ }^{6}$ Department of Electrical and Electronics Engineering, Abubakar Tafawa Balewa University, Bauchi, Nigeria
}

\section{Article Info}

Article history:

Received Feb 17, 2020

Revised Apr 19, 2020

Accepted May 12, 2020

\section{Keywords:}

Inverted pendulum

Linear matrix inequality

Linear quadratic regulator

Nonlinear system

Observer

Robustness

\begin{abstract}
An inverted pendulum is a multivariable, unstable, nonlinear system that is used as a yardstick in control engineering laboratories to study, verify and confirm innovative control techniques. To implement a simple control algorithm, achieve upright stabilization and precise tracking control under external disturbances constitutes a serious challenge. Observer-based linear quadratic regulator (LQR) controller and linear matrix inequality (LMI) are proposed for the upright stabilization of the system. Simulation studies are performed using step input magnitude, and the results are analyzed. Time response specifications, integral square error (ISE), integral absolute error (IAE) and mean absolute error (MAE) were employed to investigate the performances of the proposed controllers. Based on the comparative analysis, the upright stabilization of the pendulum was achieved within the shortest possible time with both controllers however, the LMI controller exhibits better performances in both stabilization and robustness. Moreover, the LMI control scheme is effective and simple.
\end{abstract}

This is an open access article under the CC BY-SA license.

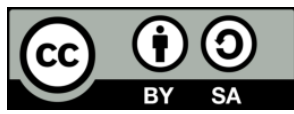

Corresponding Author:

Salinda Buyamin,

Division of Control and Mechatronics Engineering,

School of Electrical Engineering, Faculty of Engineering,

University Technology Malaysia,

Johor, Malaysia.

Email: salinda @utm.my

\section{INTRODUCTION}

Control of an inverted pendulum using various control strategies has become a topic of interest for many years owing to being an under-actuated, unstable, multivariable and non-linear. Based on the literature, the following are some of the control strategies employed for stabilization and tracking control of an inverted pendulum system; a variable speed control moment gyroscope (VSCMG) actuator was employed to control a typical pendulum configuration [1]. Coupled state-dependent Riccati equation (SDRE) method for scientifically designing nonlinear quadratic regulator (NLQR) and $\mathrm{H}$ infinity control of an under-actuated Furuta rotary pendulum was developed [2]. The main control objectives of a rotary inverted pendulum as swing-up control, stabilization control, switching control and trajectory tracking control was described in $[3,4]$ proposed RBF-ARX (state-dependent auto-regressive model with exogenous input and radial basis function network type coefficients) model-based efficient robust predictive control method for systematic inverted pendulum design. According to [5] the output feedback laws with a minimum switching rule for saturated 
switched linear systems were developed, and it provided control synthesis conditions of a spherical inverted pendulum. Improvement of Polekhin's theorem by lowering the regularity motion and a periodic solution for the carriage moving periodically on the plane was obtained in [6]. An open-source online laboratory experiment was offered by [7] for the Furuta pendulum, a system that has helped researchers to study nonlinear dynamics and control theory. An automatic self-tuning control system were proposed for inverted pendulum system via LQR controller, precise optimal stabilization was achieved [8]. A feedback linearization and sliding mode control approach were established to stabilize a class of fourth-order nonlinear systems where design parameters of the sliding surface were modified using the adaptation laws, based on the gradient descent technique [9].

However, another approach by [10], stabilized a wheeled inverted pendulum using one accelerometer with a modified mechanical structure. Similarly, approximate feedback linearization and sliding mode methods were employed to control a cart-type inverted pendulum, where stability was achieved by using an optimized hybrid algorithm based on the particle swarm optimization and genetic algorithm [11]. Linear control of the flywheel inverted pendulum was proposed in [12], in which high performances were achieved. In a different control approach, [13] controlled reaction wheel oscillation using a proportional-integral controller (PID), while A linear tracking controller was developed for velocity control of a two-wheeled inverted pendulum (TWIP) mobile robot based on its Takagi-Sugino (T-S) fuzzy model [14]. An investigation was carried out by [15] where the inverted pendulum is used and a real interpolation method is employed. The adaptive neuro-fuzzy inference system (ANFIS) was introduced to control an inverted pendulum system, where the desire position was tracked [16]. A comparison between an LQR and pole placement was presented for the stabilizing cart pendulum [17]. An algorithm in [18] was developed for single input multi output with under-actuated systems with mismatched uncertainties. In the pole-placement method, the closed-loop pole location must be determined. But the researcher may know where they are located. The optimal control method ignores finding the desired pole location, the control law of the optimal control method always optimizes the performance of the system to avoid drawbacks.

This paper presents a comparison of observer-based LQR and LMI controllers for stabilization control of an inverted pendulum system. The major problem is the pendulum Stabilization in an upright position and stoppage of cart movement at the desired location within a short time. Assessment of LMI and LQR control algorithms shows several advantages that improved closed-loop stability. Section 2 presents system describe, section 3 presents the system dynamic model and control schemes. Section 4 present results and discussion while section 5 conclusions and future recommendation.

\section{SYSTEM DESCRIPTION}

The system model is 33-000-V73 which consists of dual pendula, cart, D.C motor, and a rail. For the pendula to rotate freely through $360^{\circ}$, the two are hinged at the cart's centre [19]. The D.C motor moves the cart horizontally on the rail, freely. Figure 1 shows the mechanical system and the system is unstable whenever the pendula are positioned vertically but downright stable when positioned downwardly. Any slight deviation from the equilibrium point would render the pendulum unstable. The moving region of the inverted pendulum in which control is achievable has been shown in Figure 2.

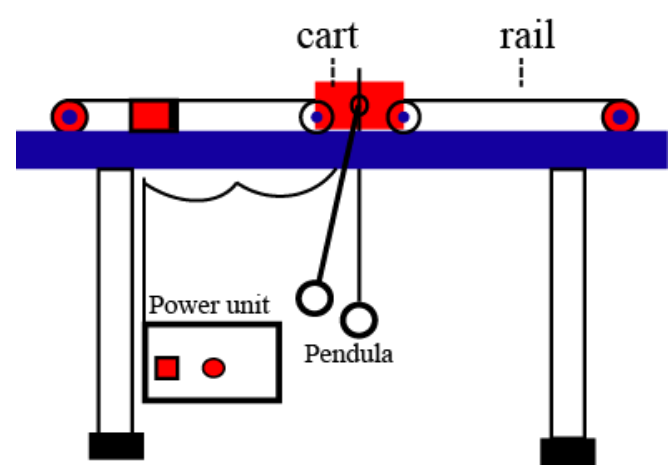

Figure 1. The 33-000-V73 laboratory-based inverted Pendulum

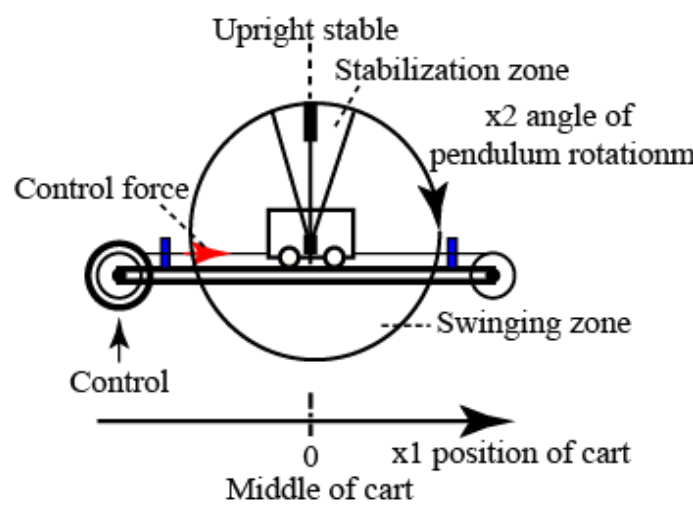

Figure 2. Schematic diagram of an inverted Pendulum 


\subsection{System modelling}

Figure 3 shows the system representations, where $x, f(t)$, and $\theta$ are the cart displacement, the applied force $(\mathrm{N})$ and the pendulum angle respectively. $I$ is the moment of inertia $\left(\mathrm{kg} / \mathrm{m}^{2}\right)$ of the rod from the centre of mass, $\mathrm{M}$ is the cart's mass $(\mathrm{kg})$ and $l$ is the length $(\mathrm{m})$ of the pendulum. The constants, $b$, and $c$ are the cart's viscous and translation damping $(\mathrm{Ns} / \mathrm{m})$ respectively. The system parameters are as recorded in Table 1 [19].

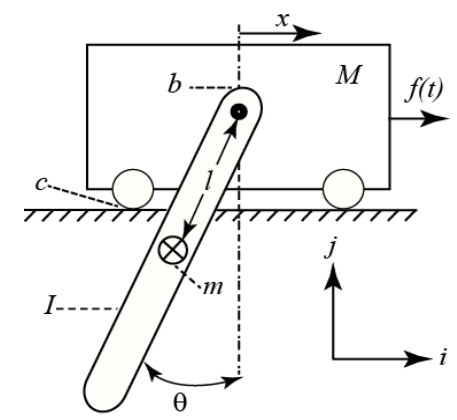

Table 1. System parameters [19]

\begin{tabular}{ll}
\hline Parameter & Value \\
\hline Mass of the cart (M) & $2.4 \mathrm{~kg}$ \\
Mass of pole (m) & $0.23 \mathrm{~kg}$ \\
Length of pole (1) & $0.38 \mathrm{~m}$ \\
Moment of inertia of the pol (1) & $0.099 \mathrm{~kg} / \mathrm{m}^{2}$ \\
Coefficient of friction of cart (b) & 0.05 \\
Damping coefficient of pendulum (d) & $0.005 \mathrm{Nms} / \mathrm{rad}$ \\
Gravity (g) & $9.8 \mathrm{~m} / \mathrm{s}^{2}$ \\
\hline
\end{tabular}

Figure 3. Schematic diagram

Based on Figure 3, the system's overall dynamic equations are obtained as:

$$
\left\{\begin{array}{c}
(M+m) \ddot{x}+c \dot{x}+m l \cos \theta \ddot{\theta}+m l \sin \theta \dot{\theta}^{2}=f(t) \\
\left(m l^{2}+I\right) \ddot{\theta}+m l \ddot{x} \cos \theta+m g l \sin \theta+b \dot{\theta}=0
\end{array}\right.
$$

The dynamic equation can, however, be represented in a state-space form as:

$$
\begin{aligned}
& \dot{x}=A x+B u \\
& y=C x
\end{aligned}
$$

and the states vector of the system expressed as:

$$
z=\left[\begin{array}{c}
z_{1} \\
z_{2} \\
z_{3} \\
z_{4}
\end{array}\right]=\left[\begin{array}{c}
\theta \\
\dot{\theta} \\
x \\
\dot{x}
\end{array}\right]
$$

where $\theta, \dot{\theta}, \mathrm{x}$ and $\dot{\mathrm{x}}$ are the pendulum angle, angular velocity, cart displacement and velocity of the cart respectively. The system matrix was obtained as [19];

$$
A=\left[\begin{array}{cccc}
0 & 1 & 0 & 0 \\
6.263 & 0 & 0 & 0 \\
0 & 0 & 0 & 1 \\
0.3358 & 0 & 0 & 0
\end{array}\right] B=\left[\begin{array}{c}
0 \\
7.0501 \\
0 \\
10.6649
\end{array}\right] \quad C=\left[\begin{array}{llll}
1 & 0 & 0 & 0 \\
0 & 0 & 1 & 0
\end{array}\right] \quad D=\left[\begin{array}{l}
0 \\
0
\end{array}\right]
$$

\section{CONTROL SYSTEM DESIGN}

\section{1. $L Q R$ control}

In the LQR control system, a control law is selected to regulate the state $x$ and to get the performance index minimized:

$$
J=\int_{0}^{\infty} x^{T}(t) Q x(t)+u^{T}(t) R u(t)
$$

where $J$ is the performance index, $R>0$ and $Q \geq 0$ are the weight matrices for the control variable $u(t)$ and state variable $x(\mathrm{t})$ respectively. Figure 4 shows a typical LQR control system. 


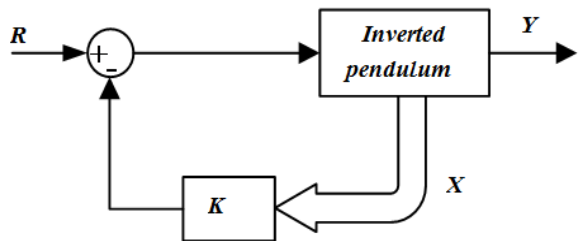

Figure 4. Typical LQR control system

$R$ and $Q$ are positive definite and the semi-positive definite matrices respectively. Thus, $\mathrm{K}$ can be obtained to satisfy the feedback control law [20-22];

$$
u=-K x=-R^{-1} B^{T} P x
$$

where; $P$ is the solution of the Riccati equation:

$$
\begin{aligned}
& A^{T} P+P A+Q-P B R^{-1} B^{T} P=0 \\
& K=R^{-1} B^{T} P
\end{aligned}
$$

The closed-loop controller gains were found as $K=$ [20.9777; 8.3690; -3.9528; -4.1689].

\subsection{Observer feedback control design}

The estimator poles were chosen ten times as faster as the system poles and the control law with the observer design is combined to get a compensator as shown in Figure 5 [23, 24]. The observer gain $L$ was obtained using MATLAB routine called "place". The observer pole was assigned as $P$. Therefore, the observer gain is obtained using equation (12) as:

$$
L=\operatorname{place}\left(A^{\prime}, C^{\prime}, P\right)^{\prime}
$$

This generated an observer gain that placed the poles in the desired position. The following parameters were used in the design of the observer in MATLAB. The weight due to angle and position values are Qdiag. $[25,0,250,0]$ and $R=1.6$. Thus, the observer gain and the closed-loop system gain was obtained as; $\mathrm{K}=[55.5439 ; 22.2266 ;-12.5000 ;-12.0038]$ and

$$
L=1.0 e+003 *\left[\begin{array}{cc}
0.0106 & -0.0708 \\
0.0415 & -1.3843 \\
0.1393 & 0.1695 \\
3.6546 & 3.8795
\end{array}\right]
$$

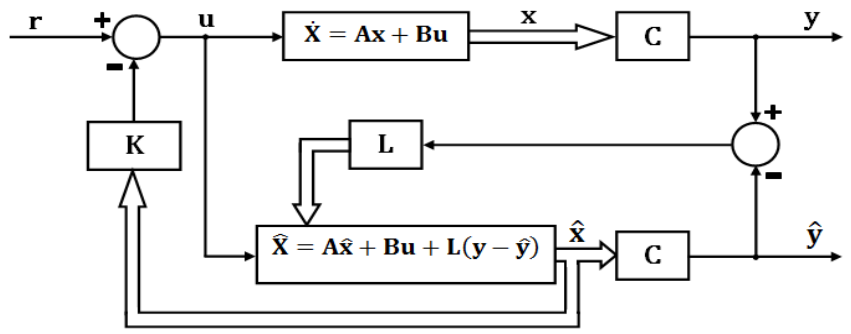

Figure 5. Observer feedback control system

\subsection{Proposed LMI controller design}

Stability and transient response of linear systems depend on the locations of the poles in the complex plane. Consider a linear dynamic system;

$$
\dot{X}=A_{c} X
$$

The Lyapunov theorem states that the system in equation (10) is said to be asymptotically stable once a real symmetric matrix $P$ satisfying the following LMIs exists [25, 26]: 
$A_{c} P+A_{c} A^{T}<0, \quad P=P^{T}>0$

The LMIs in (11) provides the conditions for the stability of the system in (10). The left half plane and LMI region is as presented in Figures 6 and7.

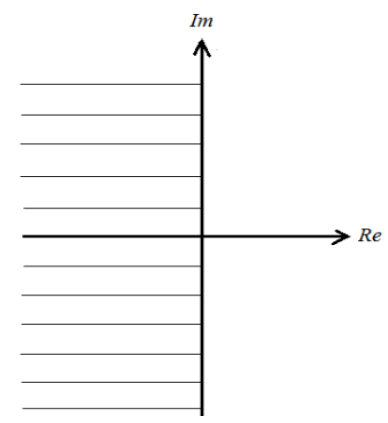

Figure 6. Left half-plane

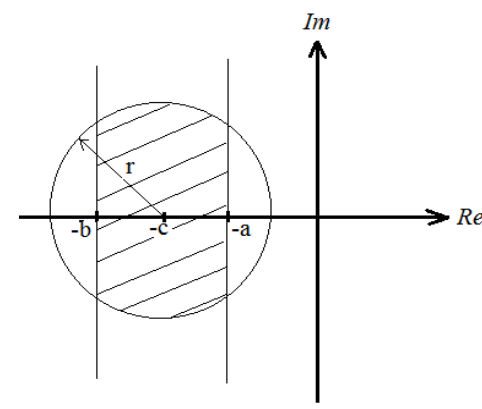

Figure 7. LMI region

All the poles of the system in (10) will be lying in the LMI region of Figure 7 if and only if there exists asymmetrical positive definite matrix $P$ such that:

$$
\begin{aligned}
& A_{c} P+P A_{c}{ }^{T}+2 a P<0, \\
& A_{c} P+P A_{c}{ }^{T}+2 b P>0, \\
& {\left[\begin{array}{cc}
-r P & c P+P A_{c}{ }^{T} \\
c P+A_{c} P & -r P
\end{array}\right]<0, \quad P=P^{T}>0}
\end{aligned}
$$

The LMIs in (12) and (13) represent the vertical strip, while the LMI in (14) represents the circle centred at $(c, 0)$ with radius $r>0$. The controller gains $K$ and the reference input scaling factor $N$ were found as [20.9777; 8.3690; -3.9528; -4.1689] and [-461.5637 - 178.3047 155.2348 104.0856] respectably by using MATLAB codes.

\section{RESULTS AND DISCUSSION}

In this section, using the step input in MATLAB software the proposed control schemes were implemented. Figure 8 shows the open-loop response and Table 2 recorded the frequency, eigenvalues, and the damping ratio of the open-loop system which confirms the system is completely unstable. The system is completely stable after applying the observer-based LQR controller as shown in Figure 9, whereby all poles of the system were located in the negative half-plane. This can also be confirmed based on the recorded data of the eigenvalues, damping and frequency as in Table 3.

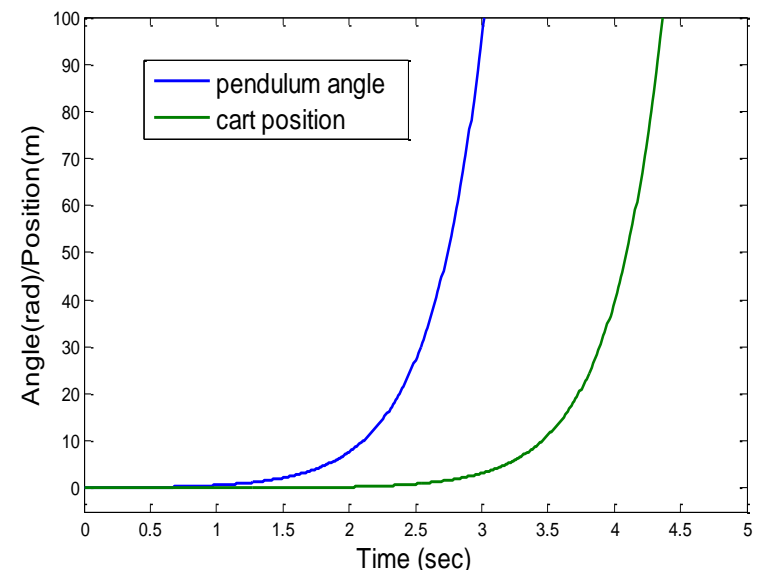

Table 2. Open-loop simulation data

\begin{tabular}{lll}
\hline Frequency $(\mathrm{rad} / \mathrm{s})$ & Eigenvalue & Damping ratio \\
\hline $0.00 \mathrm{e}+000$ & $0.00 \mathrm{e}+000$ & $-1.00 \mathrm{e}+000$ \\
$0.00 \mathrm{e}+000$ & $0.00 \mathrm{e}+000$ & $-1.00 \mathrm{e}+000$ \\
$2.52 \mathrm{e}+000$ & $2.52 \mathrm{e}+000$ & $-1.00 \mathrm{e}+000$ \\
$2.52 \mathrm{e}+000$ & $2.52 \mathrm{e}+000$ & $-1.00 \mathrm{e}+000$ \\
\hline
\end{tabular}

Figure 8. Open loop response of the system 


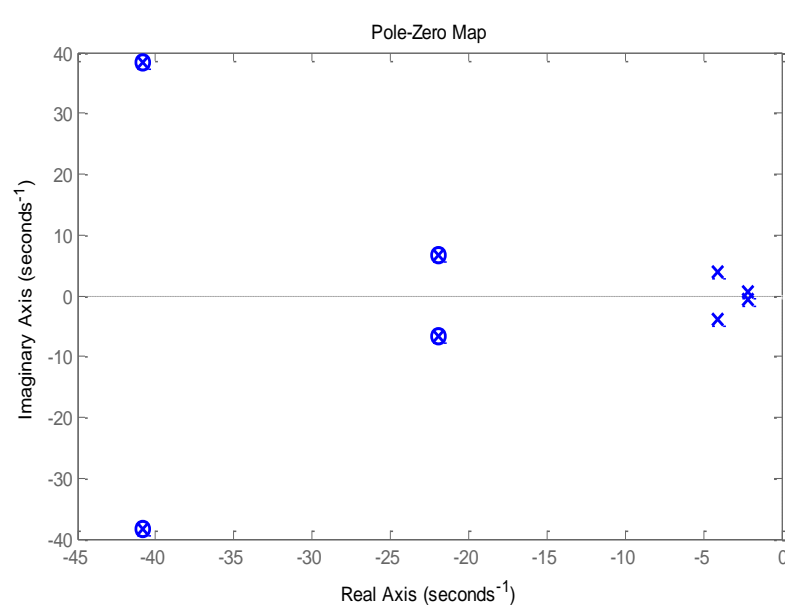

\begin{tabular}{lll}
\multicolumn{3}{c}{ Table 3. Closed-loop simulation data } \\
\hline $\begin{array}{l}\text { Frequency } \\
(\mathrm{rad} / \mathrm{s})\end{array}$ & Eigenvalue & $\begin{array}{l}\text { Damping } \\
\text { ratio }\end{array}$ \\
\hline $1.00 \mathrm{e}+001$ & $-7.15 \mathrm{e}+000+7.01 \mathrm{e}+000 \mathrm{i}$ & $7.14 \mathrm{e}-001$ \\
$1.00 \mathrm{e}+001$ & $-7.15 \mathrm{e}+000+7.01 \mathrm{e}+000 \mathrm{i}$ & $7.14 \mathrm{e}-001$ \\
$2.28 \mathrm{e}+000$ & $-2.18 \mathrm{e}+000+6.56 \mathrm{e}-001 \mathrm{i}$ & $9.58 \mathrm{e}-001$ \\
$2.28 \mathrm{e}+000$ & $-2.18 \mathrm{e}+000+6.56 \mathrm{e}-001 \mathrm{i}$ & $9.58 \mathrm{e}-001$ \\
$1.00 \mathrm{e}+002$ & $-7.15 \mathrm{e}+000+7.01 \mathrm{e}+001 \mathrm{i}$ & $7.14 \mathrm{e}-001$ \\
$1.00 \mathrm{e}+002$ & $-7.15 \mathrm{e}+000+7.01 \mathrm{e}+001 \mathrm{i}$ & $7.14 \mathrm{e}-001$ \\
$2.28 \mathrm{e}+001$ & $-2.18 \mathrm{e}+001+6.56 \mathrm{e}-001 \mathrm{i}$ & $9.58 \mathrm{e}-001$ \\
$2.28 \mathrm{e}+001$ & $-2.18 \mathrm{e}+001+6.56 \mathrm{e}-001 \mathrm{i}$ & $9.58 \mathrm{e}-001$ \\
\hline
\end{tabular}

Figure 9. Observer close loop poles and zeros map

The cart position and swing angle of the system were as shown in Figure 10, simulated with an initial condition of $0.1 \mathrm{rad}$. The systems stabilized at $2.4 \mathrm{sec}$ with 0.262 undershoot of cart position and 0.07 of the swing angles. Moreover, observer-based state feedback was designed to estimate the system output and generate the control signal that yields the desired closed-loop performance. The tick poles are the observer poles while the star-like poles are the system poles. This implies that the observer poles are more negative away from system poles. Thus, the closed-loop poles of the observed states' feedback system have system poles and the observer poles. They were designed separately and combined to form an observer feedback control system. Therefore, the observer poles are chosen in such a way that the observer response is much faster than the system response so that the observer has less effect on the system.

Besides, the LMI controller was designed and compared with observer-based LQR. In this control schemes, the closed-loop poles need to be placed in the LMI region of the complex left-half plane to achieve a stabilized system and good transient response. In designing LMI based controller, the transient parameters were selected as; $r=200$ which is the radio of the circle, $c=100$ which is the centre of the circle and $a=3$ and $\mathrm{b}=200$ which are two points on the circle. The best value of $t$ should be negative for feasibility, thus obtained as $-3.669348 \mathrm{e}-05$ and f-radius saturation is $0.000 \%$ of $R$ which is equal to $1.00 \mathrm{e}+09$, and Table 4 recorded the simulation data of the LMI control algorithms.

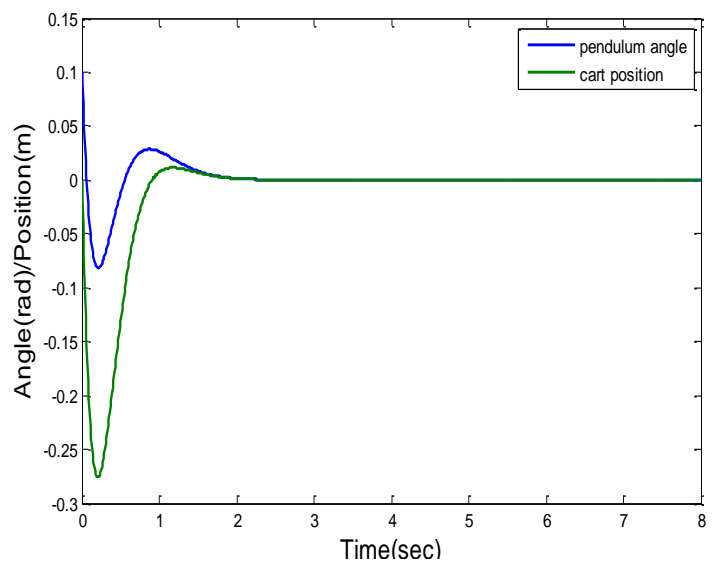

Table 4. LMI closed-loop simulation data

\begin{tabular}{lll}
\hline Frequency $(\mathrm{rad} / \mathrm{s})$ & Eigenvalue & Damping ratio \\
\hline $5.46 \mathrm{e}+00$ & $-3.88 \mathrm{e}+00+3.84 \mathrm{e}+00 \mathrm{i}$ & $7.11 \mathrm{e}-01$ \\
$5.46 \mathrm{e}+00$ & $-3.88 \mathrm{e}+00-3.84 \mathrm{e}+00 \mathrm{i}$ & $7.11 \mathrm{e}-01$ \\
$1.76 \mathrm{e}+00$ & $-1.73 \mathrm{e}+00+2.82 \mathrm{e}-01 \mathrm{i}$ & $9.87 \mathrm{e}-01$ \\
$1.76 \mathrm{e}+00$ & $-1.73 \mathrm{e}+00-2.82 \mathrm{e}-01 \mathrm{i}$ & $9.87 \mathrm{e}-01$ \\
\hline
\end{tabular}

Figure 10. Closed loop response of the system

The observer-based LQR controller does its job of maintaining the pendulum angle in an upright position, but its response is sluggish as compared to the LMI based controller. The controller's performances as in Figures 10, 11, and Table 5 show clearly that LMI controller is superior over observer-based LQR controller. Also, integral square error, integral absolute error and mean absolute error were used as the performance indexes, and based on the recorded data as shown in Table 5, both controller performances excellently as they recorded less error. However, LMI based controller shows a better performance. 


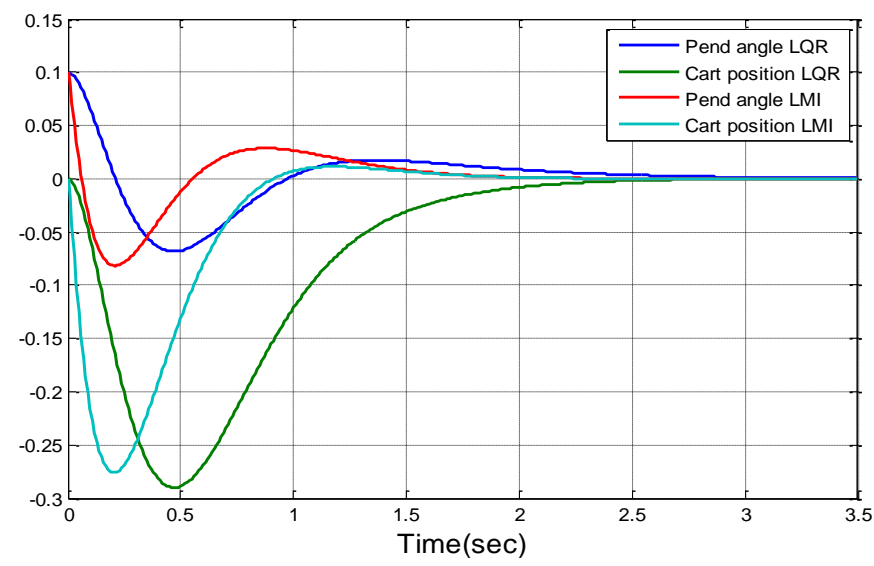

Figure11. Comparing the performances of the controllers

Table 5. Performance indexes

\begin{tabular}{llllll}
\hline Controllers & Max. undershoot (\%) & Settling time(s) & ISE & IAE & MAE (\%) \\
\hline Observer-based LQR & 0.07 & 2.4 & $7.82 \times 10^{-6}$ & $6.95 \times 10^{-6}$ & 83.60 \\
LMI & 0.082 & 1.7 & $5.45 \times 10^{-6}$ & $4.79 . \times 10^{-6}$ & 87.01 \\
\hline
\end{tabular}

\section{CONCLUSION}

In this paper, the performances of the observer-based LQR and LMI controllers were investigated for upright stabilization control of nonlinear inverted pendulum. Observer-based LQR and LMI controllers were designed to stabilize the pendula. Time response specifications, Integral absolute error, integral square error and mean absolute error were employed to investigate the performances of the proposed controllers. Based on simulation results and performance index analysis, a better performance was achieved using the LMI controller. To further reduce the amplitude and frequencies of the oscillation, frictional coefficients should be taking into consideration.

\section{ACKNOWLEDGEMENTS}

The authors gratefully acknowledged the support of Universiti Teknologi Malaysia (Vote No. R.J130000.7351.4B428) and Abubakar Tafawa Balewa University Bauchi for the resources

\section{REFERENCES}

[1] João F. S. Trentin, S. da Silva, and H. Schaub, "Variable speed control moment gyroscope in an inverted pendulum," Journal of Dynamic Systems Measurement and Control, vol. 141, no. 11, pp. 111012-1-9, 2019.

[2] X. Wang, E. E. Yaz, and S. C. Schneider, "Coupled state-dependent riccati equation control for continuous-time nonlinear mechatronics systems," Journal of Dynamic Systems Measurement and Control, vol. 140, no. 11, pp. 111013-1-10, 2018.

[3] M. Fatihu Hamza, H. Jen Yap, I. Ahmed Choudhury, A. Ismail Isa, A. Yahaya Zimit, and T. Kumbasar, "Current development on using Rotary Inverted Pendulum as a benchmark for testing linear and nonlinear control algorithms," Mechanical Systems and Signal Processing, vol. 116, pp. 347-369, 2019.

[4] X. Tian, Hui Peng, Feng Zhou, and X. Peng, "RBF-ARXmodel-based fast robust MPC approach to an inverted pendulum," ISA Transactions, vol. 93, pp. 255-267, 2019.

[5] C. Duan and F. Wu, "New results on continuous-time switched linear systems with actuator saturation," Proceedings of the ASME 2013 Dynamic Systems and Control Conference, vol. 2, 2013.

[6] R. Srzednicki, "On periodic solutions in the Whitney's inverted pendulum problem," Discrete \& Continuous Dynamical Systems - Series S, vol. 12, no. 7, pp. 2127-2141, 2019.

[7] D. Galan, D. Chaos, L. de la Torre, E. Aranda-Escolastico, and R. Heradio, "Customized online laboratory experiments: A general tool and its application to the furuta inverted pendulum [Focus on Education]," IEEE Control Systems Magazine, vol. 39, no. 5, pp. 75-87, Oct. 2019.

[8] M. Waszak and R. Łangowski, "An automatic self-tuning control system design for an inverted pendulum," IEEE Access, vol. 8, no. 2, pp. 26726-26738, 2020.

[9] M. J. Mahmoodabadi and H. K. Haghbayan, "An optimal adaptive hybrid controller for a fourth-order underactuated nonlinear inverted pendulum system," Transactions of the Institute of Measurement and Control, vol. 42, no. 2, pp. 285-294, 2019. 
[10] Q. Xu, G. Stepan, and Z. Wang, "Balancing a wheeled inverted pendulum with a single accelerometer in the presence of time delay," Journal of Vibration and Control, vol. 23, no. 4, pp. 604-614, 2017.

[11] M. A. Sahnehsaraei, M. J. Mahmoodabadi, and A. Bagheri, "Pareto optimum control of a 2-DOF inverted pendulum using approximate feedback linearization and sliding mode control," Transactions of the Institute of Measurement and Control, vol. 36, no. 4, pp. 496-505, 2014.

[12] M. Olivares and P. Albertos, "Linear control of the flywheel inverted pendulum," ISA Transactions, vol. 53, no. 5, pp. 1396-1403, 2014.

[13] J. F. Silva Trentin, T. P. Cenale, S. da Silva, and J. M. de Souza Ribeiro, "Attitude control of inverted pendulums using reaction wheels: Comparison between using one and two actuators," Proceedings of the Institution of Mechanical Engineers, Part I: Journal of Systems and Control Engineering, vol. 234, no. 3, pp. 420-429, 2019.

[14] M. Muhammad, Amir A. Bature, U. Zangina, S. Buyamin, A. Ahmad, and M. A. Shamsudin, "Velocity control of a two-wheeled inverted pendulum mobile robot: a fuzzy-model-based approach," Bulletin of Electrical Engineering and Informatics, vol. 8, no. 3, pp. 808-817, 2019.

[15] P. T. Tin, T. H. Quang Minh, T. T. Trang, and N. Q. Dung, "Using real interpolation method for adaptive identification of nonlinear inverted pendulum system," International Journal of Electrical and Computer Engineering, vol. 9, no. 2, pp. 1078-1089, 2019.

[16] M. A. A. Al-Mekhlafi, H. Wahid, and A. Abd Aziz, "Adaptive Neuro-fuzzy control approach for a single inverted pendulum system," International Journal of Electrical and Computer Engineering, vol. 8, no. 5, pp. 3657-3665, 2018.

[17] M. Fauziyah, Z. Amalia, I. Siradjuddin, D. Dewatama, R. P. Wicaksono, and E. Yudaningtyas, "Linear quadratic regulator and pole placement for stabilizing a cart inverted pendulum system," Bulletin of Electrical Engineering and Informatics, vol. 9, no. 3, pp. 914-923, 2017.

[18] D. Ha Vu, S. Huang, and T. Diep Tran, "Hierarchical robust fuzzy sliding mode control for a class of Simo underactuated systems with mismatched uncertainties," TELKOMNIKA Telecommunication, Computing, Electronics and Control, vol. 17, no. 6, pp. 3027-3043, 2019.

[19] M. Idi, N. M. Tahir, and A. G. Ibrahim, "Real-time optimal implementation of stabilizing controller for inverted pendulum," Journal of Engineering and Technology, vol. 9, no.2, 2018.

[20] N. M. Tahir, S. M. Hassan, Z. Mohamed, and A. G. Ibrahim, "Output-based input shaping for optimal control of single-link flexible manipulator," International Journal on Smart Sensing and Intelligent Systems, vol. 10, no. 2, pp. 367-386, 2017.

[21] N. M. Tahir, A. A. Bature, U. I. Bature, A. U. Sambo, and A. Y. Babawuro, "Vibration and tracking control of a single link flexible manipulator using LQR and command shaping" Journal of Multidisciplinary Engineering Science and Technology, vol. 3, no. 3, pp. 45-67, 2016.

[22] H. Liman, N. M. Tahir, G. Sani, E. C. Anene, and A. Y. Babawuro, "Comparative studies of hybrid model-dependent and model-free controller application on crane system," Sensors \& Transducers, vol. 230, no. 2. pp. 31-38, 2019.

[23] K. Ogata, "Modern Control Engineering-5th edition,” New Jersy: Prentice-Hall, 2010.

[24] I. Siradjuddin, Z. Amalia, E. Rohadi, B. Setiawan, A. Setiawan, R. I. Putri, and E. Yudaningtyas, "State-feedback control with a full-state estimator for a cart-inverted pendulum system," International Journal of Engineering \& Technology, vol. 7, no. 4.36, pp. 1428-1434, 2018.

[25] M. S. Alam and S. Mandal, "LMI based robust control of inverted pendulum system," In: Dawn S., Balas V., Esposito A., Gope S. (eds) Intelligent Techniques and Applications in Science and Technology, ICIMSAT 2019. Learning and Analytics in Intelligent Systems, vol 12. Springer Cham, pp 420-428, 2020.

[26] S. Kavirayani and G. V N. Kumar, "Flower pollination for rotary inverted pendulum stabilization with delay," TELKOMNIKA Telecommunication Computing Electronics and Control, vol. 15, no. 1, pp. 245-253, 2017.

\section{BIOGRAPHIES OF AUTHORS}
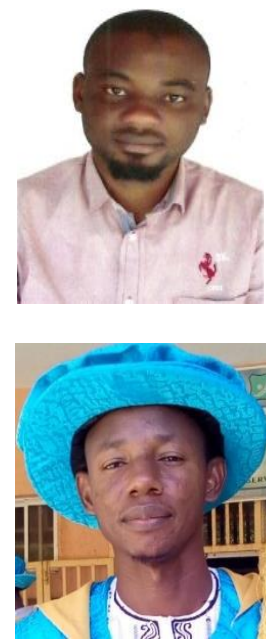

Nura Musa Tahir received the B.Eng. degree in Electrical Engineering from Bayero University, Kano in 2012 and M.Eng. Degree in Mechatronics and Automatic Control from the Universiti Teknologi Malaysia in 2016. He has been involved in research at Mechatronics systems and Robotics Laboratory in Universiti Teknologi Malaysia on vibration control, robotics and Mechatronics system design. He has been a lecturer at the Department of mechatronic and system Engineering, Abubakar Tafawa Balewa University, Bauchi Nigeria since 2014. His main research interests include Vibration Control, Mechatronics Systems Design, Control System Design, and Robotics.

Mustapha Muhammad is currently an Associate Professor in the Department of Mechatronic Engineering Bayero University, Kano, Nigeria. He received his Bachelor of Engineering and Master of Engineering degrees from Bayero University, Kano, Nigeria in January 2001 and February 2007 respectively. He received his PhD in Electrical Engineering (Robotics) in March 2014 from Universiti Teknologi Malaysia. His research interest includes the areas of artificial neural networks, fuzzy modelling, and control, intelligent control theories and robotics. 


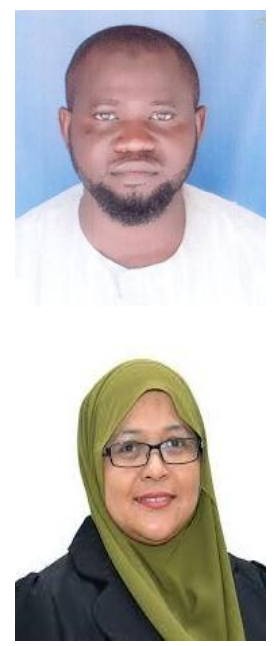

Musa Idi obtained his MSc. Degree in Applied Instrumentation and Control from the Glasgow Caledonian University, Scotland, in 2012 and a B.Eng. Degree in Electrical and Electronics Engineering from Abubakar Tafawa Balewa University, Bauchi in 2006. He worked as an Engineer in the Nigerian Television Authority Bauchi Nigeria between 2009 and 2011 before joining Abubakar Tafawa Balewa University Bauchi Nigeria as a lecturer in the Department of Mechatronics and Systems Engineering in 2013. He conducted, supervised and published research articles in the area of Automation, Control, and Robotics. His research areas of interest include optimal control, nonlinear control, intelligent control, system identification and robotics.

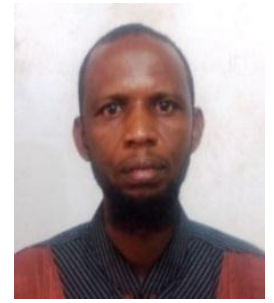

Salinda Buyamin is currently an associate professor at the School of Electrical Engineering, Faculty of Engineering, UTM. She received her Bsc. in Electrical Engineering in 1998from the University of Toledo, Ohio, USA. She has joined the school of Electrical Engineering, UTM since November 2001. She completed her MSc in Automation and Control in 2003 and obtained her PhD in 2007 from the University of Newcastle upon Tyne, UK. Her current research interest includes Modelling and Simulation of Dynamic Systems, Control and Development of Electric Drives System, System Identification and Estimation, Optimisation and Intelligent Control.

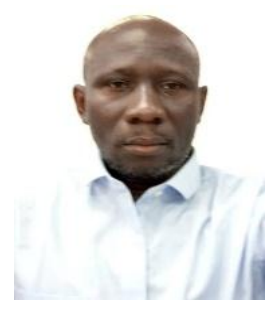

Ladan Maijama'a holds the following: National Diploma and Higher National Diploma in Electrical Electronics Engineering from Kaduna Polytechnic, Nigeria. Post Graduate Diploma and a Master's degree in Electrical Electronics Engineering from Abubakar Tafawa Balewa University, Bauchi, Nigeria. And also hold Post Graduate Diploma in Education from Federal College of Education Kano, Nigeria. He is currently undergoing his doctoral studies in Electrical Electronics Engineering Department at Abubakar Tafawa Balewa University, Bauchi, Nigeria. His current research focuses on Control System Engineering on Unmanned Aerial Vehicle. He is working with Federal Polytechnic, Bauchi, Nigeria as a Principal Lecturer in the Department of Electrical Electronics Engineering

Sa'id Musa Yarima is currently a PhD student with the Department of Electronics and Computer Engineering, University Teknologi Malaysia, UTM, since 2017. He obtained both his B.Eng and M.Eng degrees from the Abubakar Tafawa Balewa University (ATBU) Bauchi in 2008 and 2014 respectively. Before the start of a full academic carrier as a University lecturer in the Department of Electrical and Electronics Engineering of the Abubakar Tafawa Balewa University (ATBU) Bauchi in 2009, he had had both constant and intermittent touch with the Television and the Power companies in Nigeria. His major duties include teaching, research, and supervision of undergraduate students. He has a great interest in the research areas of digital signal processing (DSP), internet-of-things (IoT) and communications. 